\title{
O PERFIL DO JUIZ RACIONAL-EMOCIONAL: LINEAMENTOS DA TEORIA ERIGIDA POR LÍDIA REIS DE ALMEIDA PRADO
}

\author{
André Luiz Staack ${ }^{1}$ \\ Gabriela Rangel da Silva²
}

\section{RESUMO}

Este artigo tem por finalidade abordar acerca da teoria construída por Lídia Reis de Almeida Prado, dando ênfase aos aspectos que conectam a formação do perfil de juiz racional-emocional com as categorias e conceitos erigidos por Carl Gustav Jung em seu estudo clínico. Para o alcance do objetivo proposto, o método de abordagem empregado foi o indutivo e o levantamento de dados foi realizado através da técnica da pesquisa bibliográfica de fonte secundária. Nas considerações finais, concluiu-se que o perfil de juiz racional-emocional é sumariamente relevante e encontra-se em consonância com a realidade jurídica circundante hodierna.

Palavras-Chave: Juiz Racional-Emocional; Psicologia Analítica Junguiana; Emoção; Animus; Decisão Judicial.

\section{THE PROFILE OF THE RATIONAL-EMOTIONAL JUDGE: LINEAMENTS OF THE THEORY ADDRESSED BY LÍDIA REIS DE ALMEIDA PRADO}

\begin{abstract}
This article aims to address the theory constructed by Lídia Reis de Almeida Prado, emphasizing the aspects that connect the formation of the rational-emotional judge profile with the categories and concepts erected by Carl Gustav Jung in his clinical study. In order to reach the proposed objective, the method used was the inductive method and the data collection was performed through the technique of secondary source bibliographic research. In the final considerations, it was concluded that the profile of rational-emotional judge is summarily relevant and is in line with the legal reality surrounding today.
\end{abstract}

Keywords: Rational-Emotional Judge; Junguian Analytical Psychology; Emotion; Animus; Judicial Decision.

\footnotetext{
${ }^{1}$ Mestre em Ciência Jurídica pela Universidade do Vale do Itajaí - UNIVALI. Mestre em Estudos Políticos pela Universidade de Caldas - UCaldas/Colômbia. Especialista em Direito Penal e Processual Penal pela Univali (convênio com a Escola do Ministério Público de Santa Catarina. Bacharel em Direito pelo Centro Universitário de Brusque. Oficial de Justiça e Avaliador lotado no Fórum da Comarca de Brusque/SC. Professor na Uniasselvi/Assevim - Brusque/SC e na IBES/Unisociesc - Blumenau/SC. E-mail: staack@tjsc.jus.br.

2 Mestre em Ciência Jurídica pela Universidade do Vale do Itajaí - UNIVALI. Mestre em Estudos Políticos pela Universidade de Caldas - UCaldas/Colômbia. Especialista em Direito do Trabalho e Processo do Trabalho pela Pontifícia Universidade Católica de Porto Alegre - PUCRS. Bacharel em Direito pelo Centro Universitário Franciscano. Advogada com inscrição sob o número 90.386 OAB/RS. Professora na IBES/Unisociesc Blumenau/SC. E-mail: gaberds@gmail.com.
}

Revista de Teorias da Justiça, da Decisão e da Argumentação Jurídica | e-ISSN: 2525-9644 | Salvador | v. 4 | n. 1 | p. 62 - 79 | 


\section{INTRODUÇÃO}

Este artigo visa enaltecer os aspectos destacados por Lídia Reis de Almeida Prado em sua obra “O juiz e a emoção: aspectos da lógica da decisão judicial”, mormente os que se relacionam à construção e afirmação de um perfil de juiz denominado racional-emocional.

O critério metodológico utilizado para essa investigação e a base lógica do relato dos resultados apresentados residem no método indutivo (PASOLD, 2015). Na fase de tratamento dos dados, utilizou-se o método cartesiano (PASOLD, 2015).

Este artigo, portanto, tem como objetivo geral apontar aspectos destacados da teoria de Lídia Reis de Almeida Prado, em especial àqueles que servem de base para edificação sólida de um perfil de juiz denominado racional-emocional. Os objetivos específicos são: a) consignar as categorias e conceitos básicos da Psicologia Analítica Junguiana; b) registrar a conexão da Psicologia Analítica Junguiana com a teoria edificada por Lídia Reis de Almeida Prado; c) relacionar os pontos de destaque que levam a construir e afirmar o perfil de juiz denominado racional-emocional.

Na delimitação do tema, levanta-se o seguinte problema: o perfil de juiz racionalemocional, construído por Lídia Reis de Almeida Prado em sua teoria, deve ser considerado hodiernamente o perfil mais adequado, coerente e integrativo?

Para o equacionamento do problema, levanta-se a seguinte hipótese: a teoria de Prado, de fato, ao apontar pontos de conexão da Psicologia Analítica Junguiana com a importância devida do ato de julgar, consegue, de maneira eficaz, construir e afirmar um perfil de juiz que, diante dos novos movimentos sociais e das novéis teorias da decisão judicial, acaba por traduzir a ideal conexão da razão com as emoções inerentes ao julgador.

As técnicas utilizadas neste estudo serão a pesquisa bibliográfica, a categoria e o conceito operacional, quando necessário (PASOLD, 2015). Outros instrumentos de pesquisa, além daqueles anteriormente mencionados, poderão ser acionados para que o aspecto formal deste estudo se torne esclarecedor ao leitor.

\section{DOS CONCEITOS BÁSICOS DA PSICOLOGIA ANALÍTICA EDIFICADA POR CARL GUSTAV JUNG}

Revista de Teorias da Justiça, da Decisão e da Argumentação Jurídica | e-ISSN: 2525-9644 | Salvador | v. 4 | n. 1 | p. 62 - 79 | Jan/Jun. 2018 
É indubitável que, nos dias atuais, o Direito não se encontra mais nos moldes defendidos pelos antigos positivistas - defensores de um Direito puramente estático e altamente formalista -, nem sequer pode ser encarado num viés jusnaturalista, já que, em virtude da complexidade dos fatos sociais, o fenômeno jurídico, gradativamente, foi migrando de um estado de inércia performativa para ganhar asas e alocar-se cada vez mais em mundo jurídico dinâmico e implacável. Isso, contudo, é um assunto que hoje desafia a Ciência do Direito, já que esse dinamismo acabou por fazer nascer movimentos que se utilizam, até em demasia, do subjetivismo, do sentimentalismo e do uso irrestrito de Argumentos arbitrários. É o caso do ativismo judicial, do decisionismo judicial e, quando indevidamente aplicado, da judicialização da política.

Foi em virtude desses e de outros fatores que serão apontados no decorrer do artigo que ensejou o estudo detido de Lídia Reis de Almeida Prado da influência da Emoção no processo decisório judicial. Para tanto, interdisciplinarmente e com maestria, a autora utilizase, dentre outros Argumentos, da base da psicologia analítica construída largamente por Carl Gustav Jung em toda sua trajetória clínica. Nasceu, desse estudo, a obra denominada "O juiz e a emoção: aspectos da lógica da decisão judicial” (com primeira edição no ano de 2003).

A obra de Prado, que se preocupa com o Direito enquanto prestação jurisdicional, “[...] pretende evidenciar a importância da anima $^{3}$ do Juiz na decisão” (PRADO, 2013, p. 28). Assim, desde já, a autora, em sua introdução, deixa claro que o seu campo de estudo resta restrito aos Juízes do sexo masculino, já que, como oportunamente se verá, a Anima é apontada como lado feminino da psique masculina. Já o Animus, o lado masculino da psique feminina, é tratado de maneira casuística pela autora (mais precisamente no item 7 do capítulo VI - PRADO, 2013, p. 89-90), tão somente como forma de diferenciar da imagem arquetípica da Anima.

Antes de abordar especificamente sobre as contribuições teóricas de Prado, vale trazer à baila, a fim de auxiliar a ambientação do Leitor, alguns conceitos básicos da Psicologia Analítica construída por Jung, a fim de que seja possível compreender com exatidão, no momento oportuno, os Argumentos defendidos pela autora em sua obra.

A psicanálise, campo fértil de estudo oriundo da medicina, nasceu nas mãos do médico neurologista Sigismund Schlomo Freud, mais conhecido como Sigmund Freud. Segundo Capra, ““[...] Freud descobriu praticamente sozinho o inconsciente e sua dinâmica. Enquanto os behavioristas se recusavam a reconhecer a existência do inconsciente humano, Freud viu nele

\footnotetext{
${ }^{3}$ Itálico conforme o original.
}

Revista de Teorias da Justiça, da Decisão e da Argumentação Jurídica | e-ISSN: 2525-9644 | Salvador | v. 4 | n. 1 | p. 62 - 79 | Jan/Jun. 2018 
uma fonte essencial do comportamento” (CAPRA, 2012, p. 158). Foi ele, portanto, a partir de seu conceito de Inconsciente pessoal e de sua relação para o desenvolvimento humano, o responsável pela edificação de um campo que, até hoje, desafia o imaginário coletivo e, principalmente, põe em xeque tudo o que já fora construído anteriormente pela psicologia tradicional (se assim não faz, ao menos complementa).

Capra, nesse diapasão, revela ainda que Freud, em sua reconhecida psicologia profunda, “[...] assinalou que a nossa consciência representa apenas uma fina camada assente sobre um vasto domínio inconsciente - a ponta de um iceberg, por assim dizer, cujas regiões encobertas são governadas por poderosas forças instintivas” (CAPRA, 2012, p. 158). É por meio do processo psicanalítico, portanto, que “[...] essas tendências profundamente submersas da natureza humana podem ser reveladas” (CAPRA, 2012, p. 158).

Importa registrar, nesse ponto, que a contribuição freudiana, de fato, foi e é de sumária importância para a compreensão do indivíduo e, principalmente, para o desenvolvimento da psique humana, razão pela qual ela foi largamente discutida por diversos pensadores (na sua maioria clínicos), dentre eles Jung e Adler, gerando, inclusive, teorias argumentativas que questionam e, em muitos aspectos, complementam o que já fora inicialmente edificado pelo médico austríaco.

Do ponto vista freudiano, “[...] os conteúdos do inconsciente se reduzem às tendências infantis reprimidas ${ }^{4}$, devido à incompatibilidade de seu caráter” (JUNG, 2015, p. 15). Entretanto, para Jung, o Inconsciente não inclui apenas conteúdos reprimidos, mas também comporta “[...] todo o material psíquico que subjaz o limiar da consciência” (JUNG, 2015, p. 15). Há, portanto, no conceito junguiano de Inconsciente pessoal uma complementação do conceito freudiano, já que para aquele o Inconsciente aporta mais do que meras tendências infantis reprimidas, abarcando outros aspectos que permitem, quando projetados para o Consciente, um Processo de Individuação eficiente.

O Inconsciente é denominado pessoal, nas palavras de Jung, tendo em vista que “[...] os materiais contidos nesta camada são de natureza pessoal” (JUNG, 2015, p. 24), caracterizando, “[...] em parte, por aquisições derivadas da vida individual e em parte por fatores psicológicos, que também poderiam ser conscientes” (JUNG, 2015, p. 24). Os conteúdos inconscientes são de natureza pessoal, destarte, “[...] quando podemos reconhecer em nosso

\footnotetext{
${ }^{4}$ Itálico conforme o original.
} 
passado seus efeitos, sua manifestação parcial, ou ainda sua origem específica” (JUNG, 2015, p. 24).

Nesse contexto, Jung advoga que “[...] que quem progredir no caminho da realização do si-mesmo ${ }^{5}$ inconsciente trará inevitavelmente à consciência conteúdos do inconsciente pessoal, ampliando o âmbito de sua personalidade” (JUNG, 2015, p. 24). Ainda aponta que essa ampliação se refere, “[...] em primeiro lugar, à consciência moral, ao autoconhecimento” (JUNG, 2015, p. 24), ou seja, aos “[...] desejos, lembranças, tendências, planos, etc” (JUNG, 2015, p. 25). O restante, “[...] em regra geral, aparece mediante a análise dos sonhos” (JUNG, 2015, p. 25).

Interessante a perspectiva junguiana da projeção do Inconsciente sobre o Consciente, já que, de fato, ao trazer, no primeiro momento, os desejos, lembranças, tendências, planos à consciência, por meio da análise ou da simples atividade habitual, estará o indivíduo ampliando seus horizontes, se autoconhecendo como se deve e, consequentemente, possibilitando uma melhor relação com o mundo exterior.

Mais fascinante, contudo, é a concepção junguiana da relação dos sonhos com a prática projetiva do Inconsciente, já que, no senso comum, somos levados a acreditar que os sonhos nada mais são do que meros recortes e/ou fragmentos sem importância fruto da complexidade factual hodierna. Entretanto, nesse cenário, Jung consigna que “[...] é muito interessante observar como às vezes os sonhos fazem emergir os pontos essenciais, um a um, em perfeita ordem” (JUNG, 2015, p. 25).

Todo esse material acrescentado à consciência, seja por meio do autoconhecimento ou da análise detida dos sonhos, além de ampliar os horizontes e aprofundar um autoconhecimento, principalmente, nas palavras de Jung, “[...] humaniza o indivíduo, tornando-o modesto” (JUNG, 2015, p. 25). Certamente que uma conexão plena entre o Consciente e o Inconsciente, por meio de um processo de compensação (complementariedade) ${ }^{6}$, permite uma melhor adequação do indivíduo consigo mesmo e, por conseguinte, aloca-o de maneira mais adequada e coerente no mundo que o circunda.

Outra categoria de suma importância para a compreensão da teoria junguiana é o Inconsciente coletivo, impessoal ou suprapessoal. É assim chamado coletivo, “[...] porque é

\footnotetext{
${ }^{5}$ Itálico conforme o original.

${ }^{6}$ JUNG, Carl Gustav. O eu e o inconsciente. p. 67: “[....] os processos inconscientes se acham numa relação compensatória em relação à consciência. Uso de propósito a expressão ‘compensatória’ e não a palavra 'oposta’, porque o consciente e inconsciente não se acham necessariamente em oposição, mas se complementam mutuamente, para formar uma totalidade: o si-mesmo (Selbst)”. (Itálico conforme o original).
}

Revista de Teorias da Justiça, da Decisão e da Argumentação Jurídica | e-ISSN: 2525-9644 | Salvador | v. 4 | n. 1 | p. 62 - 79 | 
desligado do Inconsciente pessoal e por ser totalmente universal; e também porque seus conteúdos podem ser encontrados em toda parte, o que obviamente não é o caso dos conteúdos pessoais” (JUNG, 2014, p. 77). São, portanto, categorias herdadas da coletividade, frutos da historicidade e da padronização cognitiva imaginativa.

É desse Inconsciente coletivo que se pode destacar a influência da mídia, do mercado, das instituições em geral (públicas e privadas) e dos marcos significativos sociais na formação do indivíduo em geral. Sabe-se como é perniciosa, em especial, a influência da mídia na consecução do Direito e de seus ramos correlatos, e como esses marcos podem agir para que a Justiça, na prática, não seja efetivada de maneira coerente e integrativa. Por tais motivos, ante a importância para a formação do indivíduo, não há como negar a intervenção dessa modalidade de Inconsciente (principalmente sua projeção para o Consciente), nem sequer é possível relegálo a segundo plano.

Em suma, Jung aduz que “[...] devemos afirmar que o inconsciente contém, não só componentes de ordem pessoal, também impessoal, coletiva, sob a forma de categorias herdadas ${ }^{7}$ ou arquétipos” (JUNG, 2015, p. 26). Assim, há que se projetar ao Consciente não somente concepções pessoais, mas sim também imagens arquetípicas coletivas que inconscientemente restam traduzindo um indivíduo pouco cônscio de sua relação consigo mesmo e, principalmente, alienado quanto à sua relação com mundo exterior.

Após aludir os conceitos de Inconscientes pessoal e coletivo, vale aludir que, embora a projeção do Inconsciente sobre o Consciente aparente ser um processo necessário e eficaz para um devido Processo de Individuação, as consequências desse processo de assimilação do Inconsciente podem produzir fenômenos indesejáveis. Segundo Jung, “[...] alguns pacientes adquirem uma consciência de si mesmos ou uma autoconfiança exagerados e até mesmo desagradáveis. [...] Outros, pelo contrário, sentem-se deprimidos, e mesmo esmagados pelos conteúdos do inconsciente” (JUNG, 2015, p. 27).

O processo de assimilação do Inconsciente, destarte, seja de maneira habitual ou em virtude da análise clínica, não detém apenas consequências eficazes, razão pela qual o seu uso descuidado ou sem um acompanhamento de qualidade pode gerar patologias psíquicas que, no caso do Direito, por exemplo, tenham o condão de comprometer, ainda mais, o bom desenvolvimento da Justiça.

\footnotetext{
${ }^{7}$ Itálico conforme o original.
} 
Inclusive a aproximação dessas duas esferas (Consciente e Inconsciente) pode dar “[...] lugar a um sentimento de superioridade que pode muito bem expressar-se como 'semelhança a Deus”” (JUNG, 2015, p. 29). O indivíduo, nessa condição, “[...] torna-se facilmente arrogante. [...] Sente-se o dono da chave que abre muitas portas, e talvez todas!” (JUNG, 2015, p. 29). Esse fenômeno é denominado, consoante Jung, de inflação psíquica, já que “[...] envolve uma 'expansão da personalidade' além dos limites individuais ou, em outras palavras, uma presunção" ${ }^{8}$ (JUNG, 2015, p. 31).

É, nesse contexto, que é possível enquadrar o fenômeno da “juizite”. Usando-se de um exemplo, Jung expõe as consequências do fenômeno da identidade destituída do humor (o que, por certo, também abarca a “juizite”, seja na sua modalidade simples ou aguda). Assim revela:

Um exemplo comum é o da identidade destituída de humor, que muitos homens estabelecem com sua ocupação ou seus títulos. O cargo que ocupo representa certamente minha atividade particular; mas é também um fator coletivo, historicamente condicionado pela cooperação de muitos e cuja dignidade depende da aprovação coletiva. Portanto, se me identificar com meu cargo ou título, me comportarei como se fosse o conjunto complexo de fatores sociais que tal cargo representa, ou como se eu não fosse apenas o detentor do cargo, mas também, simultaneamente, a aprovação da sociedade. Dessa forma me expando exageradamente, usurpando qualidades que não são minhas, mas estão fora de mim. ' $L$ ' état, c'est moi' ', é o lema de tais pessoas (JUNG, 2015, p. 31).

É possível subsumir do adrede exposto que o processo de assimilação do Inconsciente pode, portanto, gerar consequências desagradáveis e, quiçá, irreconciliáveis, já que, inclusive, é passível de acarretar o surgimento de patologias psíquicas de grande monta. É crucial, portanto, que esse processo de assimilação seja paulatino e que tenha um acompanhamento de qualidade, já que, no caso do Direito, ao indicar análise clínica para um Juiz, no mais das vezes já instituído em sua Persona, pode a situação piorar, mesmo que momentaneamente, edificando consequências que colocarão por terra o que já fora construído pela Justiça. Não há espaço, nesse momento, para teorias ou práticas que venham subverter a ordem ou colocar ainda mais o povo numa posição de vulnerabilidade frente ao Estado. Há que ser prudente (ativa e passivamente), coerente e perspicaz.

Da mesma forma que a psique pessoal pode interferir bem ou mal no Processo de Individuação, a psique coletiva, quando no processo de assimilação do Inconsciente, também

\footnotetext{
${ }^{8}$ Itálico conforme o original.

${ }^{9}$ Itálico conforme o original.
} 
pode causar estragos descomunais. Segundo Jung, “[...] se através da assimilação do inconsciente cometermos o erro de incluir a psique coletiva no inventário das funções psíquicas pessoais, ocorrerá inevitavelmente uma dissolução da personalidade em seus pares

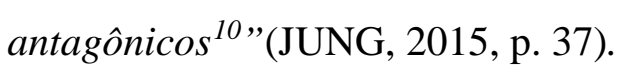

Assim, “[...] o desenvolvimento da personalidade exige sua diferenciação da psique coletiva, porquanto a ocorrência de uma diferenciação parcial ou confusa produziria imediatamente uma fusão do individual no coletivo” (JUNG, 2015, p. 40). Mais uma vez, portanto, é possível identificar que o Processo de Individuação, que torna o ser diferenciado, é uma tarefa hercúlea, razão pela qual a projeção do Inconsciente pessoal e coletivo sobre o Consciente necessita de cautela, a fim de que consequências desagradáveis não se avultem seja para o mundo interno ou para o externo.

Em virtude da influência da psique coletiva, compreendida como aquela que corresponde às categorias herdadas da coletividade (aquilo que todos compreendem como frutos do bem ou do mal), o indivíduo, a fim de se salvaguardar em meio ao caos social, acaba por utilizar-se de uma máscara que tem função de esconder todos os males de sua personalidade (as denominadas sombras). Essa máscara da psique coletiva é denominada Persona.

A Persona é “[...] uma simples máscara da psique coletiva, máscara que aparenta uma individualidade ${ }^{11}$, procurando convencer aos outros e a si mesma que é uma individualidade, quando, na realidade, não passa de um papel, no qual fala a psique coletiva” (JUNG, 2015, p. 47). Ela representa “[...] um compromisso entre o indivíduo e a sociedade, daquilo que 'alguém parece ser: nome, título, ocupação, isto ou aquilo’” (JUNG, 2015, p. 47).

A Persona, portanto, é utilizada pelo indivíduo com o fito de esconder por detrás dela, como resposta aos estímulos sociais herdados, tudo aquilo que o identifica de maneira imerecida na sua relação com a coletividade. É com o uso dela que o indivíduo aparenta ser alguém que, na verdade, não é; transparece possuir uma individualidade, mas, na realidade, é dotado de fragilidades e incompreensões.

Seja pelo desfazimento da Persona e/ou da necessidade de se autoconhecer e compreender os mundos interno e externo, que todo indivíduo, segundo Jung, necessita passar por um Processo de Individuação, compreendido este como aquele que permite “[...] a

\footnotetext{
${ }^{10}$ Itálico conforme o original.

${ }^{11}$ Itálico conforme o original.
} 
realização melhor e mais completa das qualidades coletivas do ser humano” (JUNG, 2015, p. 63); que o torna um ser único (JUNG, 2015, p. 63).

A individuação é um processo de desenvolvimento psicológico que autoriza a realização de qualidades individuais dadas; [...] em outras palavras, é um processo mediante o qual um homem se torna o ser único que de fato é” (JUNG, 2015, p. 64), não se tornando egoísta, mas sim procurando “[...] realizar a peculiaridade do seu ser” (JUNG, 2015, p. 64). É, por assim dizer, o processo que aloca o indivíduo em suas melhores condições psicológicas, possibilitando uma coerente e eficaz relação com os mundos interno e externo.

Ademais, a meta da individuação “[...] não é outra senão a de despojar o si-mesmo dos invólucros falsos da persona, assim como do poder sugestivo das imagens primordiais” (JUNG, 2015, p. 64). Esse processo, portanto, tem por fim dar ao indivíduo uma personalidade que, de fato, consiga lidar com o aspecto de complementariedade (compensação) imanente da relação do Consciente com o Inconsciente. É, logo, uma espécie de procedimento que visa contribuir para a plena compreensão do ser vivente.

Por derradeiro, antes de tratar da teoria edificada por Lídia Reis de Almeida Prado, versar-se-á acerca de dois aspectos que, com efeito, são responsáveis pela (des)construção da carga emotiva do indivíduo, quais sejam, a Anima e o Animus. Enquanto a Anima constitui “[...] o lado feminino da psique masculina”, o Animus, por sua vez, é “[...] o lado masculino da psique feminina” (HALL; NORDBY, 2014, p. 38).

Hall e Nordby expõem que “[...] quando um homem só revela traços masculinos, os seus traços femininos permanecem inconscientes e por conseguinte não se desenvolvem e continuam primitivos” (HALL; NORDBY, 2014, p. 38). Isso acarreta ao Inconsciente, segundo eles, “[...] uma qualidade de fraqueza e impressionabilidade” (HALL; NORDBY, 2014, p. 38). É o que Jung aponta, em virtude do uso indesejado da Anima, como ruptura do processo de assimilação do Inconsciente.

Ademais, consoante Jung, a Anima produz um processo de compensação com a Persona, já que esta, em virtude do uso exagerado da Anima (aqui aportada como composta de alta carga emocional), resta desconfigurada e acaba por preencher a personalidade do indivíduo masculino de “[...] caprichos, afetos, angústias, ideias obsessivas, fraquezas, vícios, etc” (JUNG, 2015, p. 84). Há, portanto, o desenvolvimento de uma fraqueza efeminada contra todas as influências do Inconsciente.

Revista de Teorias da Justiça, da Decisão e da Argumentação Jurídica | e-ISSN: 2525-9644 | Salvador | v. 4 | n. 1 | p. 62 - 79 | 
Constata-se, por óbvio, que a Anima é, de fato, mecanismo do Inconsciente que desempenha um papel importante no trato com as Emoções do indivíduo masculino, razão pela qual a sua devida compensação com a Persona, diferentemente de sua modalidade exagerada que gera fragilidades e caprichos, é peça chave para que o indivíduo racionalize e, num processo decisório, possa, enfaticamente, pautar suas decisões com Argumentos coerentes e integrativos (sem uma carga emotiva, portanto, que impeça o devida compreensão do problema).

Para tanto, defende Jung que se deve proceder à objetivação da Anima, ou seja, “[...] a negação estrita de considerar a tendência à separação do cônjuge como uma fraqueza própria” (JUNG, 2015, p. 91) (impedir o ato de ruptura). É, portanto, um processo que objetiva fazer valer a compensação eficaz (complementariedade) entre a Persona (máscara social da psique coletiva) e o Inconsciente (aqui representado pela Anima, evitando os exageros emocionais.

Assim, “[...] quem quiser incrementar o progresso em seu próprio ambiente cultural (pois toda a cultura começa com o indivíduo), deverá tentar objetivar as atuações da anima, cujos conteúdos subjazem a essas atuações” (JUNG, 2015, p. 95). Nesse sentido, nas palavras de Jung, “[...] o homem se adaptará e ao mesmo tempo se protegerá contra o invisível” (JUNG, 2015, p. 95). Atingirá, nesse momento, o equilíbrio emocional desejado para uma adequada tomada de decisão.

Esse processo de educação da Anima consiste “[...] numa rigorosa honestidade consigo mesmo e em evitar a antecipação apressada do que o outro lado quer expressar” (JUNG, 2015, p. 93). Deve-se evitar, isto posto, uma análise acelerada numa situação com alta carga emotiva, necessitando que perguntas e respostas sejam largamente efetivadas antes que o lado crítico seja aflorado. Assim, o indivíduo apenas externará de maneira Consciente tão somente após objetivar a Anima, evitando um exagero emocional.

No mesmo sentido que a Anima atinge o indivíduo masculino, o Animus, figura compensadora de caráter masculino, alcança a psique pessoal feminina. “[...] Assim como a anima produz caprichos, o animus produz opiniões; e assim como os caprichos do homem brotam de um fundo obscuro, do mesmo modo as opiniões da mulher provêm de pressupostos apriorísticos inconscientes ${ }^{12}$ ” (JUNG, 2015, p. 97).

Essas opiniões oriundas do Animus “[...] apresentam muitas vezes o caráter de sólidas convicções, difíceis de comover, ou de princípios cuja validez é aparentemente intangível” (JUNG, 2015, p. 97). Na realidade, contudo, “[...] essas opiniões são totalmente irrefletidas;

\footnotetext{
${ }^{12}$ Itálico conforme o original.
} 
existem prontinhas e são mantidas com tal firmeza e convicção pela mulher que as formula, como se esta jamais tivesse tido a menor sombra de dúvida a respeito” (JUNG, 2015, p. 97).

O Animus “[...] é projetado com a mesma frequência que a anima” (JUNG, 2015, p. 98), gerando, contudo, um quadro de rigidez opinativa no consciente feminino. Do mesmo modo que a Anima, “[...] o animus é um amante ciumento, pronto para substituir um homem de carne e osso por uma opinião sobre ele, opinião cujos fundamentos duvidosos nunca são submetidos à crítica” (JUNG, 2015, p. 99). Cabe a mulher, nesse cenário, proceder à objetivação de seu Animus, impedindo o surgimento de exageros emocionais em sua personalidade.

Em suma, a Anima e o Animus “[...] habitam uma esfera de penumbra, e dificilmente percebemos que ambos [...] são complexos autônomos que constituem uma função psicológica do homem e da mulher” (JUNG, 2015, p. 101). Sua autonomia e falta de desenvolvimento “[...] usurpa, ou melhor, retém o pleno desabrochar de uma personalidade” (JUNG, 2015, p. 101). Há, portanto, a necessidade de que homem e mulher se conscientizem de ambos institutos, convertendo-os, assim, em pontes que possam conduzi-los ao compreender de seu Inconsciente.

\section{A TEORIA EMOTIVA DE LÍDIA REIS DE ALMEIDA PRADO E O PERFIL DE JUIZ RACIONAL-EMOCIONAL: PARA ALÉM DA LÓGICA JURÍDICA TRADICIONAL}

Após aportar os conceitos e contextos operacionais da Psicologia Analítica de Jung, tão somente para facilitar a compreensão do Leitor, importa registrar, a partir de então, os Argumentos contributivos de Prado para a teoria geral do Direito, que, na sua essência, conduz para demonstrar a importância da Emoção no ato de julgar.

A teoria de Prado inicia seu percurso consignando, como já foi procedido anteriormente, alguns conceitos básicos da Psicologia Analítica de Jung. Dentre os vários, destaca-se um que, em virtude da importância para o discorrer do tema, será versado apenas nesse momento com as palavras e disposições construídas pela autora. Trata-se da figura do arquétipo.

Os arquétipos consistem “[...] em predisposições humanas típicas para agir, pensar, sentir, sendo que cada pessoa, na sua individualidade, pode vivenciá-las particularmente” (PRADO, 2013, p. 51). É um modelo ou personagem que cada indivíduo se vale para instituição e perpetuação de sua Persona, seja na sua vida pessoal ou profissional.

Revista de Teorias da Justiça, da Decisão e da Argumentação Jurídica | e-ISSN: 2525-9644 | Salvador | v. 4 | n. 1 | p. 62 - 79 | 
A partir desse conceito, Prado aduz que “[...] é possível afirmar que a ideia de Juiz ao lado da de Justiça - sempre esteve presente na vida dos diferentes povos, embora com características e roupagens diversas, constituindo, pois, um arquétipo” (PRADO, 2013, p. 56). Assim, seja a concepção de Juiz ou de justiça, ambas são consideradas, diante das particularidades de cada um, arquétipos (formas de se representar um personagem ou instituir um modelo).

Essa imagem arquetípica do Juiz “[...] varia no tempo e no espaço, passando pelos mesmos estágios da história da magistratura”. É, após, apenas “[...] de um breve exame dessa história, importante no processo civilizatório, surgirão os subsídios para uma reflexão a respeito da referida imagem” (PRADO, 2013, p. 56).

Mais especificadamente no Brasil, “[...] o juiz é coletivamente percebido como um personagem um tanto anacrônico, que trabalha sem a presteza esperada pelas partes, um ser distante, instalado em pomposos locais de trabalho” (PRADO, 2013, p. 59). É diante desse arquétipo do Magistrado brasileiro, identificado por Prado como ultrapassado e não condizente com a atual realidade social, que a autora busca, em seu trabalho, por desconstitui-lo, introduzindo, para tanto, alguns fatores que, enfaticamente, tem por fim fazer nascer um novo paradigma arquetípico para o representante-mor da Justiça.

O primeiro fator relaciona-se com a ideia de que os arquétipos possuem dois polos, ou seja, contêm uma polaridade. "Dentro dessa concepção, não haveria um arquétipo de Juiz ou outro de infrator. Cada um deles seria uma das extremidades de uma mesma situação arquetípica” (PRADO, 2013, p. 60). Isso denota uma concepção de que dentro de cada Magistrado há também um infrator, razão pela qual, quando do trato com o problema, cabe ao julgador identificar não só a sua postura de Juiz, mas também o seu eu-infrator.

Segundo Prado, o que costumeiramente acontece com os Juízes hodiernos é uma ruptura entre os dois polos arquetípicos (Juiz - infrator), “[...] evento interior, que depende menos da situação externa do que do desenvolvimento psicológico de cada Juiz” (PRADO, 2013, p. 60). Assim, o que pode ocorrer é que um dos polos permanece Consciente e o outro poderá, reprimido, ficar no Inconsciente, sendo projetado sobre as partes do processo (PRADO, 2013, p. 60).

Prado (2013, p. 60) assim consigna do tema:

Essa situação significa que o juiz torna-se tão somente juiz, esquecendo-se que tem como possibilidade um réu dentro de si. O ego identifica-se com a persona, fato muito lesivo, porque redunda na ofuscação da consciência por um conteúdo inconsciente. O magistrado tenta ser divino, sem máculas, 
incidindo, às vezes, na hybris (descomedimento) de se considerar a própria Justiça encarnada (porque só os deuses julgam os mortais). Esse fenômeno chama-se inflação da persona, que ocorre quando os magistrados de tal forma se identificam com as roupas talares, que não mais conseguem desvesti-las nas relações familiares ou sociais. A inflação da persona causa fragilidade ou rigidez da psique ${ }^{13}$.

Diante desse cenário, evidencia-se a importância de se edificar um perfil de Juiz (denominado por Prado de Julgador-Julgado ${ }^{14}$ ) que, de fato, leve em consideração esses dois polos arquetípicos em sua tomada de decisão, prestando, diante da consciência de suas sombras ${ }^{15}$, um melhor serviço para o Direito e, consequentemente, para a Justiça. Aquele Magistrado que, certamente, compreende suas falhas e vê em si mesmo também um possível infrator orienta sua decisão para a consecução de uma Justiça mais coerente e integrativa.

Outro fator de suma importância para Prado é o papel da Anima na tomada de Decisão Judicial. Como já exposto, a autora deu preferência (é, de fato, o objeto do seu trabalho) para análise do Anima na psique masculina, deixando o Animus, lado masculino da mulher, para um segundo plano. O arquétipo do Animus será tratado nesse trabalho, mas de uma forma mais concisa.

Nas palavras de Prado, “[...] o arquétipo da anima é muito importante, porque, sendo do mundo feminino - ligado ao sentimento - ela é uma figura compensatória para a consciência masculina” (PRADO, 2013, p. 77). Diante desse cenário psicanalítico, no que concerne a sua influência na tomada de Decisão Judicial, constata-se, diante do atual quadro do Direito brasileiro, que o estudo da importância da Emoção (do uso do sentimento) faz-se mister, seja por que ramo for, haja vista que inexorável sua influência argumentativa hodierna. Foi diante desse panorama que nasceu o estudo de Prado.

A função da Anima na psique do indivíduo masculino “[...] é fazer com que o homem entre em contato, durante o processo de individuação, com cada uma das importantes figuras arque-típicas do inconsciente coletivo” (PRADO, 2013, p. 78), quais sejam “[...] o traidor e o traído, o que ama e o que é amado, o opressor e a vítima, o nobre e o ignóbil, o Juiz e o réu”

\footnotetext{
${ }^{13}$ Itálico conforme o original.

${ }^{14}$ PRADO, Lídia Reis de Almeida. O juiz e a emoção: aspectos da lógica da decisão judicial. p. 110: “[...] Tal denominação expressa o julgador que, embora procure pautar sua vida e seu desempenho profissional pela juridicidade, sabe que tem dentro de si, como possibilidade, um réu”.

${ }^{15}$ PRADO, Lídia Reis de Almeida. O juiz e a emoção: aspectos da lógica da decisão judicial. p. 63: “[...] creio ser importante que o Juiz - mais talvez do que qualquer outro profissional - entre em contato com seus conteúdos sombrios, trazendo-os à consciência. Dessa forma, poderá talvez projetá-los menos. Isso ocorrerá se buscar entender o significado desse possível infrator que - como todo ser humano - tem dentro de si, reconhecendo-o como tal”.
} 
(PRADO, 2013, p. 78). Mais uma vez, portanto, como já exposto, aparece o perfil de Juiz Julgador-Julgado, tão sumariamente importante, segundo a autora, para a perpetuação do arquétipo de alteridade da Anima (conexão entre o eu e o outro).

Ademais, segundo a autora, desse Processo de Individuação, que decide por projetar ao Consciente dados escondidos no Inconsciente (oriundos da Anima), nasce uma habilidade criativa e “[...] um sentimento passível de ser experimentado de modo não ameaçador" (PRADO, 2013, p. 79). Além do mais, “[...] tem uma função de grande importância para o Magistrado, com reflexos na prestação jurisdicional: quando o espírito lógico do homem se mostra incapaz de discernir os fatos ocultos em seu inconsciente, ela ajuda-o a identificá-los” (PRADO, 2013, p. 79-80).

Percebe-se, portanto, que a projeção da Anima sobre o Consciente permite que algumas habilidades exsurjam nos seres que estão passando por processos de individuação. A habilidade criativa, contudo, é a mais preocupante no que tange ao atual cenário do Direito brasileiro atual, já que diversos movimentos - como o ativismo judicial, o decisionismo judicial e a judicialização das políticas públicas - já restam por defender o uso irrestrito desse lado criativo na tomada de Decisões Judiciais (sem critérios específicos, salvo o último nas palavras de Streck). Entretanto, esses movimentos, como se constata, não nasceram construindo uma base teórica sólida, nem mesmo foram edificados levando em consideração a prática jurídica, mas sim tiveram por fim autorizar Magistrados, por meio de suas canetadas, resolver os problemas da forma que melhor lhes aprouvessem (com ou sem o uso de Argumentos conglobantes). Ser criativo não pode ser sinônimo de ser arbitrário!

É bem verdade que há muito se está tentando compreender tais teorias inovadoras de Decisão Judicial, mas, com os estudos habituais, cada vez mais se vê que o uso irrestrito da criatividade só causa malefícios às partes, bem como transforma a Justiça em um frequente mercado de ações. Não há, entretanto, como tolher a criatividade dos Magistrados, já que é essencial para a solução dos complexos conflitos sociais hodiernos (hard cases), mas há que se buscar alternativas para que esses Argumentos criativos sejam aplicados de maneira coerente e integrativa. É o que defende Prado quando apoia sua defesa na projeção adequada da Anima sobre o Consciente do indivíduo masculino. Ao se projetar de maneira adequada, os aspectos conscientizados da Anima, de fato, permitem uma criatividade que não gera arbitrariedades, já que o indivíduo estará munido de sentimentos que tornam a decisão não ameaçadora para o 
sistema em geral. A decisão terá, portanto, uma parcela adequada e coerente de criatividade (nem mais, nem menos).

No mais, “[...] o arquétipo da anima ${ }^{16}$, por meio de suas manifestações, pode ser um importante aliado (embora não seja domesticável)” (PRADO, 2013, p. 80), já que alivia pressões e tensões afetivas, “[...] desenvolvendo no homem a habilidade para os relacionamentos, por possibilitar que cada um seja visto como realmente é” (PRADO, 2013, p. 80). No que concerne aos Juízes, “[...] a integração dos predicados desse arquétipo viabiliza que as partes sejam consideradas em sua humanidade e com o mínimo de preconceitos” (PRADO, 2013, p. 80). A domesticação da Anima, portanto, humaniza o Juiz, torna-o modesto e afasta preconceitos perniciosos para uma tomada coerente de Decisão Judicial.

Quanto ao Animus e sua influência no trabalho realizado pela Juíza, Prado assevera que “[...] é desejável que ela realize um trabalho interior para que, desfeita a identificação com o animus ${ }^{17}$, passe a ter condições de elaborar sentenças não apenas ditadas por esse arquétipo" (PRADO, 2013, p. 90). Somente desse modo, “[...] as suas decisões poderão ser mais sensíveis e com maior ligação com o caso concreto” (PRADO, 2013, p. 90).

Diferentemente do que ocorre com o homem e sua Anima, “[...] uma mulher sujeita ao animus e ao $\operatorname{Logos}^{18}$ é cruel, obstinada e até dominadora” (PRADO, 2013, p. 89). Como juíza, portanto, “[...] as suas decisões poderão ser proferidas de acordo com um pensamento de segunda classe, governado por convicções dissociadas, quer do caso concreto, quer das pessoas envolvidas no litígio, ou mesmo das possíveis consequências da sentença” (PRADO, 2013, p. 90). Cabe, portanto, à mulher realizar um Processo de Individuação, e nele proceder a uma projeção adequada de seu Animus sobre o Consciente, permitindo, como ocorre com o homem, o equilíbrio das Emoções e adequação, no caso do seu trabalho como Juíza, dos implicantes Argumentos Morais.

Como forma para incluir esse novo perfil de Juiz, Prado advoga que, diante do atual panorama do Direito brasileiro, “[...] torna-se necessário propiciar ao Magistrado seu aperfeiçoamento funcional e pessoal” (PRADO, 2013, p. 100). Para tanto, considera básico “[...] que se dê maior atenção ao desempenho das Escolas de Magistratura existentes no país” (PRADO, 2013, p. 100). De fato, não é a inclusão de Juízes/juízas em clínicas de análise que farão com que as Emoções sejam equilibradas (até poderia ser, mas não há como exigir dos

${ }^{16}$ Itálico conforme o original.
${ }^{17}$ Itálico conforme o original.
${ }^{18}$ Itálico conforme o original.

Revista de Teorias da Justiça, da Decisão e da Argumentação Jurídica | e-ISSN: 2525-9644 | Salvador | v. 4 | n. 1 | p. 62 - 79 | Jan/Jun. 2018 
membros da Magistratura que façam análise - até porque, como já explicitado, esse trabalho é altamente perigoso se mal orientado), mas sim é por meio de tratativas de certos assuntos nas próprias Escolas de Aperfeiçoamento de Magistrados que a projeção do Inconsciente sobre o Consciente pode se estabelecer de forma paulatina, mas efetiva.

Segundo Prado (2013, p. 105), o caminho ideal é a realização de dinâmicas de grupo orientadas por psicólogos-consultores, com a participação massiva dos Juízes, oportunidade em que seriam trabalhados, entre outros, os seguintes temas:

a. os motivos pelos quais os Juízes escolheram a profissão;

b. o fascínio que exercem sobre os julgadores as polaridades justiça e injustiça, licitude e ilicitude, crime e inocência;

c. as possíveis consequências para o Juiz do uso do poder (nesse tema, poderão ser trabalhados a inflação da persona e o estresse);

d. como lidar com a sobrecargas de estresse que o poder acarreta;

e. contato consciente com a antijuridicidade e com os elementos da sombra (oposto dos ideais individuais e coletivos);

f. a relação entre o Juiz, como parte da sociedade, e os problemas ocasionadores das ações judiciais, os quais representam, entre outras coisas, as feridas da coletividade;

g. Eros e Logos. As características referentes a Eros, que são indissociáveis do ato da tomada de decisão;

h. Ligação entre racionalidade e emoção no ato de julgar ${ }^{19}$.

Essa necessidade se faz presente, já que, segundo a autora, “[...] há sinais de que a judicatura brasileira esteja evoluindo - embora vagarosa e gradativamente - para um inédito modo de relacionamento entre o Juiz e as partes, com uma maior proximidade entre ambos e com uma inusitada forma de tutela dos Direitos” (PRADO, 2013, p. 108). Há, portanto, que tratar de temas, próprios da área ou interdisciplinares, que auxiliem na concretização desse novo modelo da judicatura, aparentemente mais preocupado com os propósitos da alteridade.

Está caindo por terra, portanto, “[...] a clássica figura, típica do dinamismo patriarcal, do magistrado neutro, ascético cumpridor da lei e distante das partes e da sociedade” (PRADO, 2013, p. 103). É a hora agora do denominado Juiz/juíza racional-emocional (PRADO, 2013, p. 103), ou seja, aquele que, de maneira adequada, consegue equilibrar seu lado racional com os seus sentimentos, projetando o seu Anima/Animus de maneira efetiva e, consequentemente, fazendo surgir Argumentos que, embora de cunhos morais, não subvertem a ordem jurídica em exercício.

\footnotetext{
${ }^{19}$ Itálico conforme o original.
} 
Por derradeiro, importa registrar que “[...] tão importante quanto os aspectos próprios da justiça feminina (o sentimento do Juiz, em face do caso concreto) são as qualidades da justiça masculina (a ordem social trazida pela norma)” (PRADO, 2013, p. 120). Consoante a autora, “[...] somente com a convivência dessas duas dimensões, presentes em Diké e Atená, parece ser exequível uma prestação jurisdicional fundada na virtude da prudência e, assim, equilibrada e harmônica” (PRADO, 2013, p. 120).

Não há, desse modo, como negar a influência da Emoção no ato julgar (nem sequer o uso de Argumentos Morais), já que não é possível simplesmente retirar as Emoções, os sentimentos e as preconcepções dos Magistrados antes da tomada de decisão. Há que se trabalhar sabendo que os sentimentos fazem parte do indivíduo e que eles, inclusive, são deveras importantes na solução dos conflitos complexos hodiernos. Para tanto, há que, tão somente, buscar alternativas, como esta apresentada por Prado, para que a justiça seja, enfaticamente, efetivada de maneira coerente e integrativa.

\section{CONSIDERAÇÕES FINAIS}

A pesquisa ora realizada tratou de abordar acerca da teoria construída por Lídia Reis de Almeida Prado, dando ênfase aos aspectos que relacionam a formação do perfil de juiz racional-emocional com as categorias e conceitos erigidos por Carl Gustav Jung em seu estudo clínico detido.

Inicialmente, abordaram-se as categorias e conceitos básicos da Psicologia Analítica Junguiana, objetivando assim auxiliar na compreensão do leitor acerca da teoria construída por Prado. Ato contínuo, versou-se mais precisamente da teoria de Prado, destacando os pontos de conexão com a teoria junguiana e apresentando, detidamente, os pontos que levaram a autora a defender e erigir um perfil de juiz denominado racional-emocional.

Com a pesquisa realizada, foi possível concluir que a ideia de um perfil de juiz racional-emocional resta, nos dias atuais, inevitável, haja vista a massiva influência da Subjetividade no ato de julgar e, consequentemente, da Emoção na construção dos argumentos jurídicos. Assim, há que partir do princípio de que as Emoções fazem parte da tomada de Decisão Judicial, já que impossível sua retirada das mentes dos Magistrados, necessitando, tão somente, que se encontre meios para efetivar o seu equilíbrio e impedir efeitos perniciosos. E nesse ponto Prado foi magistral, já que não apenas versou sobre a influência da emoção no ato

Revista de Teorias da Justiça, da Decisão e da Argumentação Jurídica | e-ISSN: 2525-9644 | Salvador | v. 4 | n. 1 | p. 62 - 79 | 
de julgar, mas também apresentou uma saída efetiva para que os juízes, de fato, profiram decisões sem se valerem de contumazes arbitrariedades.

Desse modo, confirma-se a hipótese formulada inicialmente na introdução deste artigo, já que, de fato, a teoria de Prado, enfaticamente, unindo o Direito e a Psicologia Analítica Junguiana, logrou êxito ao versar acerca da influência da Emoção no ato de julgar, apresentando, ademais, uma saída para uma formação adequada do Magistrado e, consequentemente, para o equilíbrio apropriado das Emoções no ato de julgar. E assim, derradeiramente, edificou de maneira sólida um perfil de juiz denominado racional-emocional.

\section{REFERÊNCIAS BIBLIOGRÁFICAS}

CAPRA, Fritjof. Ponto de mutação: a ciência, a sociedade e a cultura emergente. Tradução de Álvaro Cabral. São Paulo: Editora Cultrix, 2012. Título original: The turning point.

HALL, Calvin S.; NORDBY, Vernon J. Introdução à psicologia junguiana. Tradução de Heloysa de Lima Dantas. São Paulo: Cultrix, 2014. Título original: A Primer of Jungian Psychology. p. 38.

JUNG, Carl Gustav. O eu e o inconsciente. Tradução de Dora Ferreira da Silva. 27. ed. Petrópolis: Vozes, 2015. Título original: Zwei Schriften über Analytische Psychologie.

. Psicologia do inconsciente. Tradução de Maria Luiza Appy. 24. ed. Petropólis: Vozes, 2014. Título original: Zwei Schriften über Analytische Psychologie.

PASOLD, Cesar Luiz. Metodologia da pesquisa jurídica: Teoria e Prática. 13 ed. rev. atual. amp. Florianópolis: Conceito Editorial, 2015.

PRADO, Lídia Reis de Almeida. O juiz e a emoção: aspectos da lógica da decisão judicial. 6. ed. São Paulo: LTr, 2013.

Revista de Teorias da Justiça, da Decisão e da Argumentação Jurídica | e-ISSN: 2525-9644 | Salvador | v. 4 | n. 1 | p. 62 - 79 | 